\title{
ВЫЗОВ РЫНКУ ТРУДА В УСЛОВИЯХ COVID-ПАНДЕМИИ: НОВЫЕ ТЕНДЕНЦИИ КАДРОВОЙ РАБОТЫ
}

\section{CHALLENGE TO THE LABOR MARKET IN THE CONTEXT OF THE COVID PANDEMIC: NEW TRENDS IN PERSONNEL WORK}

\section{A. Kuzmicheva}

Summary. Two years in the conditions of the COVID-pandemic and COVID-restrictions for air travel have left an imprint on the structure of the labor market in the Russian Federation in general, and aviation personnel in particular. The aviation industry, which is experiencing difficulties with the volume of air transportation and the declining number of aircraft ordered for construction, did not remain on the sidelines. On the example of an aviation corporation, the specifics of the selection of aviation personnel are shown, a social study was conducted, and the problems with the selection of qualified personnel were revealed.

Keywords: labor market, aviation personnel, recruitment, aviation enterprise, shortage of qualified personnel, search and recruitment of personnel.

\author{
Кузьмичёва Алла Александровна \\ Доцент, ФГБОУ ВПО Московский авиационный \\ институт (Национально-исследовательский \\ университет) \\ allamai@list.ru
}

Аннотация. Два года в условиях COVID-пандемии и COVID — ограничений для воздушных перелётов наложили отпечаток на структуру рынка труда в РФ в целом, и авиационных кадров в частности. В стороне не осталась авиационная промышленность, испытывающая трудности с объёмом авиаперевозок и снижающееся количество заказанных к постройке воздушных судов. На примере авиационной корпорации показана специфика подбора авиационного персонала, было проведено социальное исследование, вскрыты возникшие проблемы с подбором квалифицированных кадров.

Ключевые слова: рынок труда, авиационный персонал, подбор кадров, авиационное предприятие, дефицит квалифицированных кадров, поиск и привлечение персонала.
$\mathbf{K}$ ак сложилось в экономике в целом, и в отрасли управление персоналом в частности,- авиационный персонал - это лица, имеющие специальную подготовку и осуществляющие деятельность по обеспечению безопасности полетов воздушных судов или авиационной безопасности, деятельность по организации, выполнению, обеспечению и обслуживанию воздушных перевозок и полётов воздушных судов, авиационных работ, организации использования воздушного пространства, организации воздушного движения и включены в перечни по видам авиации ${ }^{[1]}$.Будучи органичной частью экономики, рынок труда чутко реагирует на макроэкономические изменения. Ввиду этого, падение спроса на авиаперевозки на фоне пандемии корона вирусной инфекции, наблюдаемое с конца 2019 года может привести к сокращению до 4,8 млн. работников авиационной отрасли в мировом масштабе. Об этом сообщили в Международная ассоциация воздушного транспорта (IATA) и Международной федерации транспортных рабочих (ITF).«Авиация столкнулась с беспрецедентной катастрофой в сфере занятости. Авиакомпании существенно сократили расходы, но при нынешних условиях у них осталось всего 8,5 месяца. Десятки тысяч рабочих мест уже потеряны, и, если правительства не предоставят дополнительную финансовую помощь, их число, вероятно, увеличится до сотен тысяч»,- пояснил генеральный директор IATA Александр де Жуньяк. [2.]. Российский рынок труда чутко реагирует на вызовы пандемии. Экономисты регулярно мониторят данный рынок [3]. Очевидно, что в сложившихся условиях особое значение приобретает эффективный подбор персонала.

Проблемой качественного подбора квалифицированных специалистов озадачены многие российские экономисты, такие как Ворожейкин И.Е.[4], Кузьмичева А.А.[5], Орлов А.И.[6], Черкасов В.В. [7] и др.

Предметом исследования статьи выступает процесс поиска и привлечения персонала в авиационной корпорации. Исследование основано на анализе внутренних документов предприятия, внешних и внутренних сайтов, а также опросе специалистов по кадрам.

Первым этапом обозначенного исследования стало выяснение этапов работы, проводимой кадрами. Работа с претендентами на вакантную должность в авиационной компании можно изобразить схематично следующим образом: 


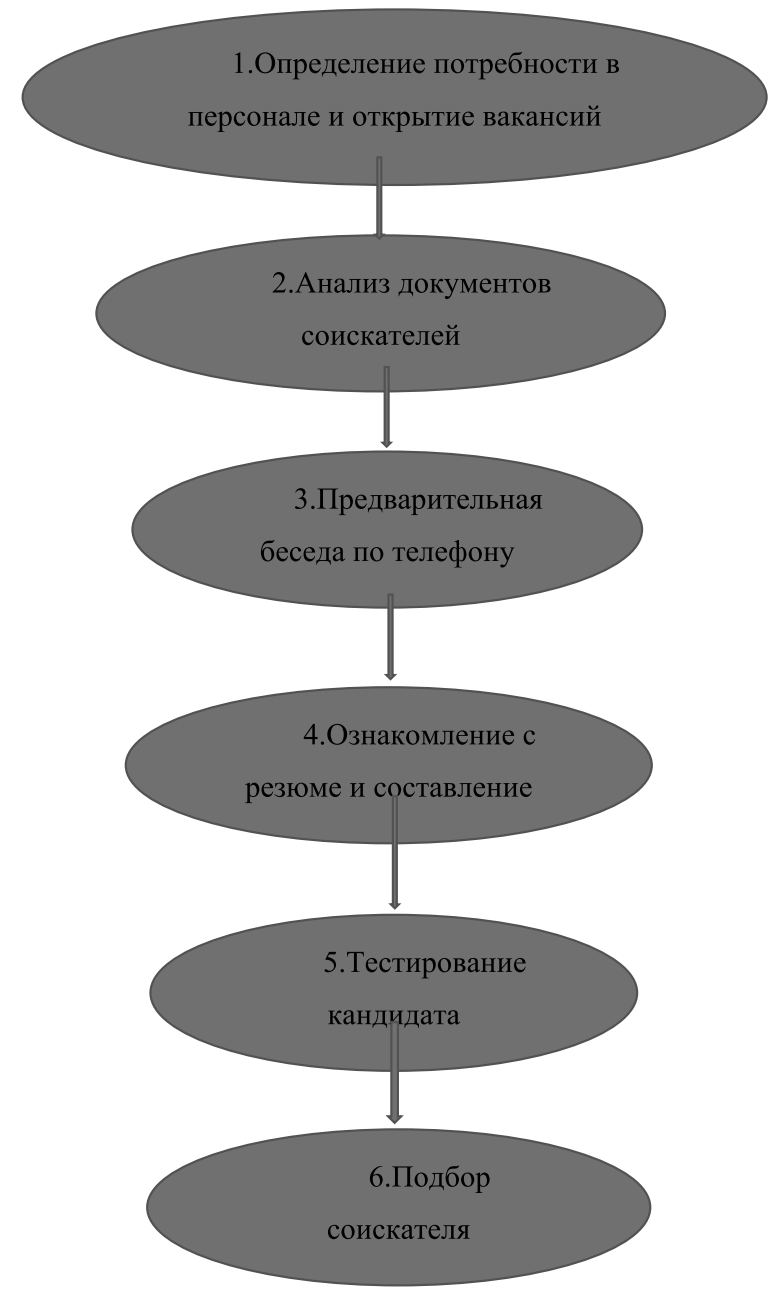

Рис. 1. Изображение этапов подбора персонала авиационного предприятия.

Необходимо более подробно остановиться на шестом этапе - подборе персонала в авиационной компании.

Подбор персонала документирован следующими документами:

1. Должностной инструкцией с указанием назначения работы данного сотрудника, его основных обязанностей, числом работников, за которых он несет ответственность, порядка подотчетности.

2. Стандартизированной заявкой на подбор специалиста, в которой руководитель подразделения указывает дополнительные требования: личностные характеристики сотрудника на этом участке работы, опыт трудовой деятельности в тех или иных областях или организациях, образование. Поскольку исследование проводилось в технологическом подразделении, то требуется отметить, что профиль требований к инженеру-технологу формируется из следующих критериев отбора: знания, навыки, личностные качества. Требования соответствуют стандартизированным должностным инструкциям.

На предприятии используются преимущественно внешние источники подбора кадров, а именно сотрудничество с вузами, интернет-сайты (собственный и специализированные). Информация о вакантных должностях размещается как на официальном сайте организации, так и на различных сайтах по поиску работы, таких как: HR-Сообщество и публикации [8], kadry-opk.ru [9], headhunter.ru [10] и др. С целью привлечения перспективных кадров в ОАО «Ил» организовывают ознакомительную, производственную и другие виды практик для учащихся профильных учебных организаций.

На предприятии имеется потребность в двух видах подбора кадров: широкий подбор и узкий подбор. Широкий подбор проводится в следующем порядке: 
Таблица 1. Анализ текучести и движения кадров

\begin{tabular}{|l|l|l|l|l|l|}
\hline Показатель & $\mathbf{2 0 1 8}$ г. & $\mathbf{2 0 1 9}$ г. & $\mathbf{2 0 2 0}$ г. & $\begin{array}{l}\text { Tемп прироста } \\
\mathbf{2 0 1 8 / 2 0 1 9} \text { гг }\end{array}$ & $\begin{array}{l}\text { Tемп прироста } \\
\mathbf{2 0 1 9 / 2 0 2 0} \text { гг }\end{array}$ \\
\hline Численность персонала всего & 2436 & 2646 & 2958 & 8,62 & 11,79 \\
\hline Численность ППП персонала, В т.ч. & 2182 & 2407 & 2823 & 10,31 & 17,28 \\
\hline Рабочие различных категорий & 697 & 699 & 771 & 0,29 & 10,30 \\
\hline Инженеры-(техники) конструкторы & 481 & 484 & 573 & 0,62 & 18,39 \\
\hline Принято, в т.ч. & 442 & 450 & 645 & 1,81 & 43,33 \\
\hline до 30 лет & 110 & 157 & 308 & 42,73 & 96,18 \\
\hline старше 30 лет & 332 & 293 & 337 & $-11,75$ & 15,02 \\
\hline Уволено, в т.ч. & 379 & 407 & 450 & 7,39 & $-12,29$ \\
\hline до 30 лет & 87 & 95 & 100 & 9,20 & $-23,16$ \\
\hline старше 30 лет & 292 & 312 & 284 & 6,85 & $-8,97$ \\
\hline По собственному желанию & 223 & 219 & 230 & $-1,79$ & 3,65 \\
\hline По инициативе руководства & 139 & 140 & 170 & 19,42 & $-36,14$ \\
\hline $\begin{array}{l}\text { Другое (уход на пенсию, } \\
\text { по состоянию здоровья) }\end{array}$ & 17 & 22 & 24 & 29,41 & 9,09 \\
\hline Коэффициент выбытия & 0,16 & 0,15 & 0,17 & $-1,13$ & $-21,54$ \\
\hline Коэффициент приема & 0,18 & 0,17 & 0,22 & $-6,27$ & 28,22 \\
\hline Коэффициент стабильности & 0,85 & 0,85 & 0,87 & 0,36 & $-1,13$ \\
\hline Текучесть кадров & 15,56 & 15,38 & 16,57 & 3,85 \\
\hline
\end{tabular}

просматриваются поступившие резюме, анализируются анкеты. Далее происходит отбор - собеседование, профессиональное тестирование, проверка рекомендаций и послужного списка (при наличии). Однако на практике зачастую используется смешанный вариант- сочетание подходов широкого и узкого отбора, т.к. узкий подбор требует больших знаний и опыта, а также более трудоемок по времени.

Основной сложностью процесса подбора кадров является качественное закрытие вакансий в связи с выросшей потребностью предприятия в квалифицированных кадрах по причине новых вызова рынка.

Для проверки гипотезы «Процесс подбора квалифицированных кадров осуществляется быстро, но некачественно» использовался метод анализа документов (Годовые отчеты, внутренняя документация отдела кадров) и метод интервью.

Первым шагом для рассмотрения проблемы подбора кадров необходимо провести анализ движения промышленно-производственного персонала (ППП) на предприятии, так как именно прием и увольнение сотрудников определяет особенности подбора и расстановки кадров. Данные для анализа взяты из Годовых отчетов за период 2018-2020 гг., а также внутренней документации отдела кадров. С целью получения представления о стабильности коллектива определим показатели: коэффициент выбытия кадров, коэффици- ент приема кадров, коэффициент стабильности кадров, показатель текучести кадров.

В результатах интервью с Начальником кадров будут прокомментированы тенденции, отображенные в таблице. В ходе исследования процесса поиска и привлечения персонала было проведено интервью с начальником отдела кадров для определения сложившейся ситуации на предприятии. При ответе на вопрос о скорости подбора персонала, респондент отметил достаточно быстрое закрытие вакансий: «Закрытие вакансий происходит достаточно быстро - 7-10 дней. Среди всех кандидатов не всегда знаешь, кто из них более опытный и более квалифицированный. Отсюда и бывает, что закрываем быстро, а потом увольняются или их увольняют. И тут уже встает вопрос о качестве закрытия. Руководство требует практически мгновенного закрытия вакансий, а мы не всегда успеваем закрыть по всем критериям. С этим нужно, конечно, что-то делать. В последние годы был большой выброс персонала на рынок труда, многие предприятия проводили сокращения. Если говорить про опытных сотрудников, то идет переквалификачия с других отраслей». Комплектование кадров является одним из ключевых элементов работы службы управления персоналом любой организации, так как от качества отобранных кадров зависит эффективность деятельности организации в целом. При ответе на вопрос о том, что является качественным подбором на данном предприятии, респондент отве- 
Таблица 2. Результаты социального исследования

\begin{tabular}{|c|c|c|c|}
\hline Выявленные проблемы & Причины & Предлагаемые мероприятия & Ожидаемый результат \\
\hline $\begin{array}{l}\text { Процесс подбора } \\
\text { персонала на предприятии } \\
\text { осуществляется быстро, } \\
\text { но результат не удовлетворяет } \\
\text { требованиям руководства. }\end{array}$ & $\begin{array}{l}\text { Некачественный подбор } \\
\text { персонала отделом кадров }\end{array}$ & $\begin{array}{l}\text { Организовать более } \\
\text { качественное закрытие } \\
\text { вакансий путем внедрения } \\
\text { системы премирования } \\
\text { сотрудников отдела кадров } \\
\text { при качественном закрытии } \\
\text { вакансий }\end{array}$ & Снижение текучести кадров \\
\hline
\end{tabular}

Таблица 3. Система премирования отдела кадров

\begin{tabular}{|l|l|l|l|}
\hline Работник & Показатель & Ставка & База \\
\hline Начальник отдела кадров & Специалисты выполнили нормативы & 20 & Оклад за 12 мес. \\
\hline \multirow{2}{*}{ Специалист по подбору кадров } & $\begin{array}{l}\text { Показатель текучести новых } \\
\text { сотрудников не более 0,1 }\end{array}$ & Оклад за 12 мес. \\
\cline { 2 - 4 } & $\begin{array}{l}\text { Процент закрытия вакансий в течение } \\
\text { 2 недель более 50\% }\end{array}$ & 10 & Оклад за 12 мес. \\
\hline
\end{tabular}

тил: «Для нас качественный подбор - это уровень образования и опыт соискателя. Обязательно проводится тест на знания специффики работы. Для нас это самое важное, так как в нашей отрасли требуются хорошие специалисты». На вопрос о текучести респондент ответил следующим образом: «Конечно люди увольняются, но так везде, это закономерныц̆ процесс на предприятиях. Но все-таки нам не хватает хороших специалистов». На протяжение рассматриваемого периода общее количество персонала на предприятии постоянно росло. Это свидетельствует о том, что предприятие расширяет свою деятельность и нуждается в кадрах.

Коэффициент выбытия в 2020 году увеличился по сравнению с предыдущим годом на $2 \%$, коэффициент приема возрос с $17 \%$ до $22 \%$, а текучесть кадров увеличилась на 1,19\%. Это свидетельствует об ухудшении стабилизации коллектива предприятия за последний год. При этом можно обратить внимание на факт, что предприятие покрывает нехватку персонала в основном за счет приема молодых сотрудников, когда процент увольнения выше у квалифицированных сотрудников.

Таким образом, на авиационном предприятии сложилась проблемная ситуация в области стабильности коллектива. Это связано в первую очередь с тем, что в условиях повышенной потребности в кадрах в связи с расширением деятельности предприятия, подбор персонала в большей степени был ориентирован на скорость. Отдел кадров стремится побыстрее закрыть огромное количество свободных вакансий, выполняя план, не думая о том, что результаты не удовлетворяют руководителей. В ходе интервью респондент признал в существующих проблемах текучести на предприятии связанным с быстрым подбором персонала и, что руководство недовольно таким закрытием вакансий. Таким образом, гипотеза -«Результаты процесса подбора квалифицированных кадров не устраивает руководителей подразделения предприятия» подтверждена. Социальное исследование, проводимое в трудовом коллективе, считается эффективным в том случае, если оно приводит к конкретным результатам. В данном случае результаты можно отразить в виде таблицы.

Предлагается в Положении по предприятию закрепить следующую систему премирования, представленную в таблице 3.

По итогам проведенного исследования следует, что проблемная ситуация, сложившаяся в организации заключается в том, что имеется нехватка квалифицированных кадров, имеющих достаточный опыт работы, результат подбора которых не устраивает руководителей подразделений предприятия. Данная тенденция усиливается турбулентностью на рынке авиационных кадров, связанной с пандемией и общим кризисом на рынке труда. Для того, чтобы исключить выявленные проблемы поиска и привлечения персонала авиационного предприятия необходимо предложить и осуществить ряд мероприятий:

1. организовать более качественное закрытие вакансий путем внедрения системы премирования;

2. расширить источники и методы поиска и привлечения персонала. 
Реализация предложенных мер приведет к повышению производительности труда путем снижения текучести кадров и увеличения удельного веса квалифицированного персонала с опытом работы в общей структуре кадров. Общие расходы на проведение мероприятий ниже, чем предполагаемые доходы. Экономическая эффективность положительная. Проведенные расчеты свидетельствуют об экономической целесообразности предложенных мероприятий по совершенствованию процесса подбора кадров.

\section{ЛИТЕРАТУРА}

1. Воздушный кодекс Российской Федерации от 19 марта 1997 года № 60-Ф3. — Техэксперт. docs.cntd.ru. Дата обращения: 30. 05. 2021.

2. iz.ru-Электронный ресурс. Дата обращения 29.05.2021.

3. Обзор международной практики поддержки экономики и населения в условиях борьбы с пандемией коронавируса в Армении, Великобритании, Германии, Дании, Испании, Италии, Казахстане, Китае, Нидерландах, США, Финляндии, Франции, Швеции, Южной Корее, Японии.- Институт социальной политики НИУ ВШэ https://isp.hse.ru-Дата обращчения 30.05.2021

4. Ворожейкин И.Е. Управление социальным развитием организации.- М.: ИНФРА-М, 2015

5. Кузьмичева А.А. Проблема профессионального обучения сотрудников авиационного предприятия (в социальном аспекте)- № 1 (42)2020. С. 119-128.

6. Орлов А.И. Стимулирование как эффективный метод управления. // Российское предпринимательство. — 2015.

7. Черкасов В.В., Концепция производственного управления персоналом// Российское предпринимательство. — 2015.

8. НR-Сообщество и публикации [Электронный ресурс].—Режим до-ступа: http://hr-portal.com.ru (29.05.2021 г.)

9. KADROVIK.ru [Электронный ресурс].— - Режим доступа: http://www.kadrovik.ru (29.05.2021 г.)

10. Head Hunter [Электронный ресурс].— - Режим доступа: www.hh.ru (29.05.2021

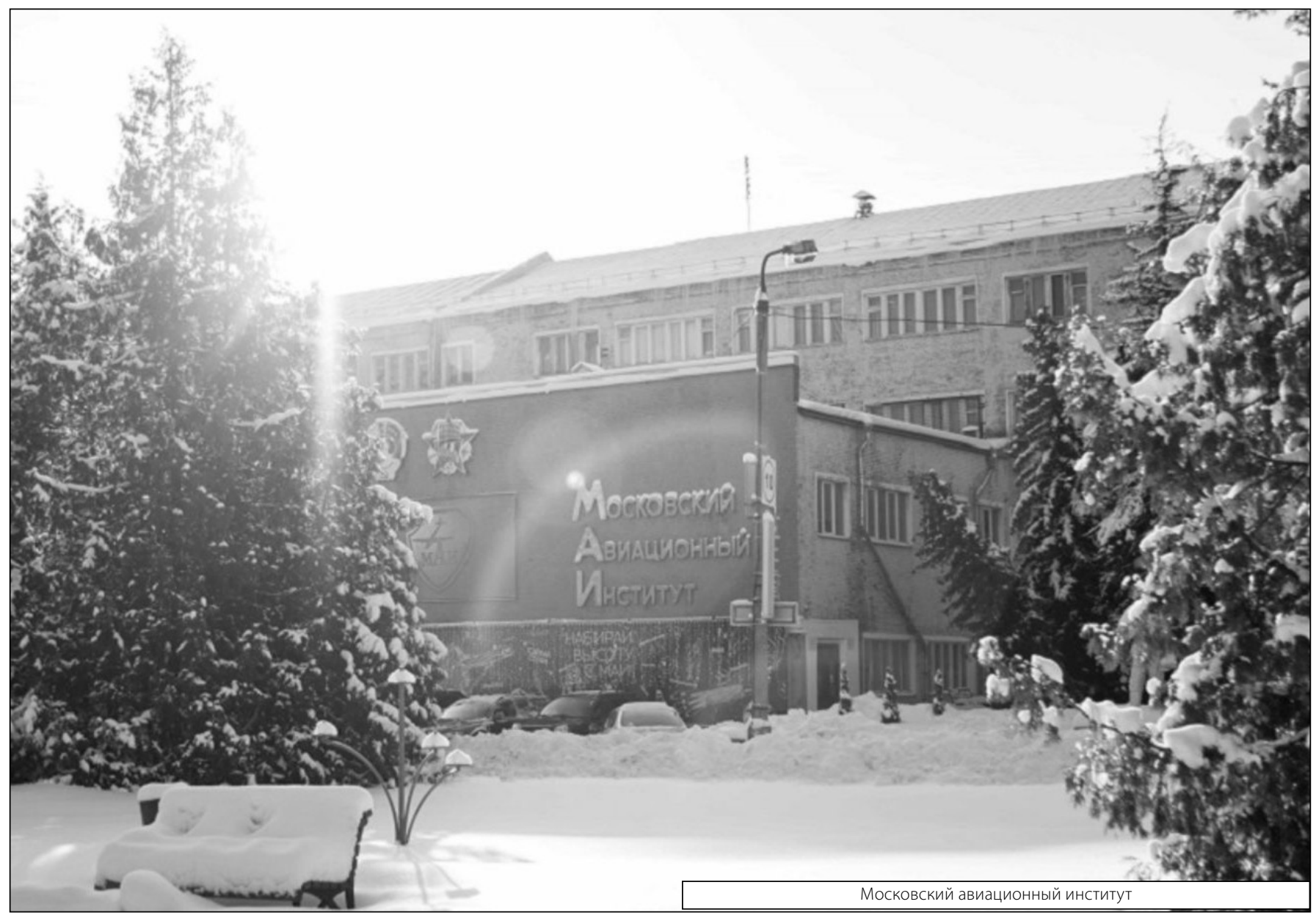

